\title{
Factor Decomposition of Carbon Emissions from Energy Consumption of Shanxi Province Based on LMDI
}

\author{
LI Ya-jie ${ }^{1, a}$, Kong Feng ${ }^{2, b}$, Wei Wei $i^{3, c}$ \\ ${ }^{1,2,3}$ School of Economics and Businesses, North China Electric Power University, Baoding 071003, \\ China.
}

a1334492142@qq.com

Keywords: Shanxi Province; Energy consumption carbon emission; Factor decomposition; LMDI

\begin{abstract}
This paper based on the "2006 IPCC guidelines for national greenhouse gas inventories" to measure a variety of energy carbon emission coefficient and calculate the carbon emission from energy consumption of Shanxi Province in 2004-2013. Using the application of logarithmic mean weight decomposition method (LMDI), Shanxi Province carbon emissions from energy consumption is divided into four aspects, economic growth, industrial structure, energy intensity, energy consumption structure. The results of the study show that: taking 2003 as a base period, economic growth is the biggest driving factor of energy consumption carbon emission in Shanxi Province; Energy intensity is the biggest factor to curb carbon emissions; industrial structure also has a promoting effect on energy consumption carbon emission, but it is obviously smaller than the effect of economic growth; energy consumption structure both has positive and negative effects on carbon emission, and its positive effect is greater than negative. Finally, many corresponding suggestions are put forward based on the results of the analysis.
\end{abstract}

\section{Introduction}

LMDI is a commonly used method of IDA, it not only can eliminate the residual items which can't be explained, but also can deal with the 0 value problems in data. Many scholars have used the LMDI method to study the carbon emission problem in China and have made great achievements in recent years. Li Guozhang and Wang Shuang used the LMDI method to decompose the energy intensity changes of 1995-2005 in China in 2008 and found that technological progress in the region factor which is displayed though regional energy intensity is the determinants of Chinese energy intensity changes[1];Song Jiekun studied the decomposition of carbon emission factors of energy consumption in Shandong province by using LMDI method in 2012 [2];Zhang Wei and Zhang Jinsuo used the LMDI method and extended Kaya model in 2013 to analysis the influence about five factors to the energy consumption carbon emissions in Shaanxi Province[3].However, the existing research results are not enough to fully reflect the characteristics of carbon emissions in different regions of China.

On the basis of these realities, this paper calculates the carbon emissions from energy consumption in Shanxi Province during 2004-2013 by using LMDI method after dividing the energy consumption of Shanxi province into four aspects, including economic growth, industrial structure, energy intensity, energy consumption structure and so on. Finally, we provide many suggestions for Shanxi province to make and adjust the policy of reducing emissions.

Method

\subsection{LMDI Model introduction}

The decomposition model of energy consumption carbon emissions is as follows.

$$
E=\sum_{i=1}^{4} Q \times \frac{Q_{i}}{Q} \times \frac{C_{i}}{Q_{i}} \times \frac{E_{i}}{C_{i}}
$$

In the above formula, $E, Q, C$ represent carbon emission, GDP and energy consumption. In detail, $Q_{i}$ is the gross domestic product of the $i$-th industry ( $i=1,2,3$ ); $C_{i}$ is the energy consumption of the $i$-th industry; $E_{i}$ is the carbon emission of the $i$-th industry. 


$$
S_{i}=\frac{Q_{i}}{Q}, \quad I_{i}=\frac{C_{i}}{Q_{i}}, \quad U_{i}=\frac{E_{i}}{C_{i}}
$$

So,

$$
E=\sum_{i=1}^{4} Q \times S_{i} \times I_{i} \times U_{i}
$$

In e q. (2), $S_{i}$ is the proportion of the $i$-th industry in Shanxi Province and it represents industrial structure effect; $I_{i}$ is the energy intensity of the $i$-th industry and it represents energy intensity effect; $U_{i}$ is the carbon emissions from a unit of energy consumption in the $i$-th industry and it represents energy consumption structure effect.

$$
\begin{aligned}
& \Delta E_{\text {tot }}=\Delta E_{e}+\Delta E_{p}+\Delta E_{s}+\Delta E_{c} \\
& \Delta E_{e}=\sum_{i=1}^{3} L\left(E_{i}{ }^{t}, E_{i}{ }^{0}\right) \ln \left(\frac{e_{i}^{t}}{e_{i}{ }^{0}}\right) \\
& \Delta E_{p}=\sum_{i=1}^{3} L\left(E_{i}^{t}, E_{i}{ }^{0}\right) \ln \left(\frac{p_{i}{ }^{t}}{{p_{i}}^{0}}\right) \\
& \Delta E_{s}=\sum_{i=1}^{3} L\left(E_{i}{ }^{t}, E_{i}{ }^{0}\right) \ln \left(\frac{s_{i}{ }^{0}}{s_{i}{ }^{0}}\right) \\
& \Delta E_{c}=\sum_{i=1}^{3} L\left(E_{i}{ }^{t}, E_{i}{ }^{0}\right) \ln \left(\frac{c_{i}{ }^{t}}{c_{i}{ }^{0}}\right)
\end{aligned}
$$

Define it:

$$
L\left(E_{i}{ }^{t}, E_{i}{ }^{0}\right)=\left\{\begin{array}{c}
\frac{E_{i}{ }^{t}-E_{i}{ }^{0}}{\ln \left(E_{i}{ }^{t} / E_{i}{ }^{0}\right)}, E_{i}{ }^{t} \neq E_{i}{ }^{0} \\
E_{i}{ }^{2} \text { 或 } E_{i}{ }^{0}, E_{i}{ }^{t}=E_{i}{ }^{0}
\end{array}\right.
$$

\subsection{Estimation of carbon emission coefficient}

Combined with "IPCC national greenhouse gas inventory guide" in 2006, the carbon emission coefficients of five main energy sources in Shanxi province were calculated. The calculation results are shown in Table 1.

Table 1 Carbon emission coefficients of various energy sources

\begin{tabular}{ccccc}
\hline Type & $\begin{array}{c}\text { Standard Coal } \\
\text { Coefficient } \\
\text { (kg Standard Coal/kg) }\end{array}$ & $\begin{array}{c}\text { Net Calorific } \\
\text { Value } \\
(\mathrm{TJ} / \mathrm{Gg})\end{array}$ & $\begin{array}{c}\text { Carbon Content } \\
(\mathrm{kg} / \mathrm{Gg})\end{array}$ & $\begin{array}{c}\text { Carbon emission } \\
\text { coefficient } \\
(\mathrm{kg} / \mathrm{kg} \text { Standard Coal) }\end{array}$ \\
\hline Raw coal & 0.7143 & 20.9084 & 26.2 & 0.7669 \\
Cleaned coal & 0.9000 & 26.3441 & 25.8 & 0.7650 \\
Coke & 0.9714 & 28.4340 & 29.2 & 0.8547 \\
Gasoline & 1.4714 & 43.0696 & 19.0 & 0.5571 \\
Natural gas & 1.3300 & 38.9307 & 15.3 & 0.4478 \\
\hline
\end{tabular}

\subsection{Estimation of carbon emission}

The calculation formula of energy consumption carbon emission of Shanxi Province is as follows.

$$
E=\sum_{i=1}^{3} \sum_{j=1}^{5} E_{i j}=\sum_{i=1}^{3} \sum_{j=1}^{5} C_{i j} \times \gamma_{j}
$$

In e q.(9), $E_{i j}$ is the carbon emissions from energy consumption of the $j$-th energy in the $i$-th industry. $C_{i j}$ is the consumption of the $j$-th energy in the $i$-th industry. $\gamma_{j}$ the carbon emission coefficient of the $j$-th energy. Get 2004-2012 energy consumption carbon emissions of Shanxi Province in Table 2. 
Table 2 2004-2012 energy consumption carbon emissions of Shanxi Province

\begin{tabular}{cccc}
\hline Time & Carbon emissions & Fixed base growth Rate(\%) & MoM growth Rate (\%) \\
\hline 2003 & 6012.908223 & $/$ & $/$ \\
2004 & 6371.730834 & 5.97 & 5.97 \\
2005 & 6814.508886 & 13.33 & 6.95 \\
2006 & 7563.699888 & 25.80 & 11.00 \\
2007 & 7831.487819 & 30.24 & 3.54 \\
2008 & 8438.962486 & 40.35 & 7.76 \\
2009 & 8993.324183 & 49.57 & 6.57 \\
2010 & 9431.637559 & 56.86 & 4.87 \\
2011 & 10003.46659 & 66.37 & 6.06 \\
2012 & 10511.47552 & 74.82 & 5.08 \\
\hline
\end{tabular}

As can be seen from the table 2, carbon emission has been rising since 2003 in Shanxi province. Growth rate of carbon emission was rising as the same time.

\section{Results}

Taking 2003 as the base period, we can get the five factors' year by year effect and cumulative effect shown in Table 3, table 4.

Table 3 Energy consumption carbon emissions of various factors year by year effect in 2004-2012(Unit: 10,000 tons)

\begin{tabular}{cccccc}
\hline Time & $\begin{array}{c}\text { Economic } \\
\text { Growth }\end{array}$ & $\begin{array}{c}\text { Industrial } \\
\text { Structure }\end{array}$ & $\begin{array}{c}\text { Energy } \\
\text { Intensity }\end{array}$ & $\begin{array}{c}\text { Energy } \\
\text { Consumption } \\
\text { Structure }\end{array}$ & Complex \\
\hline 2004 & 2249.510267 & 201.7277551 & -1121.748243 & -6.168702358 & 1323.321077 \\
2005 & 1175.687484 & 338.0600454 & -1882.360365 & 55.78858709 & 1532.8242485 \\
2006 & 3686.100958 & 409.058266 & -2270.31682 & 88.4741095 & 1913.316514 \\
2007 & 5138.463558 & 483.77616 & -3166.634105 & -204.3768585 & 2251.228755 \\
2008 & 6554.632165 & 510.8290184 & -4383.458699 & 50.17024655 & 2732.172731 \\
2009 & 6452.104695 & 233.2607472 & -4009.226839 & 177.5623139 & 2853.700917 \\
2010 & 8320.012629 & 432.5927046 & -5340.926748 & 42.44930375 & 3454.127889 \\
2011 & 10138.83954 & 611.0373815 & -6532.466452 & -104.3179595 & 4113.09251 \\
2012 & 10668.18684 & 353.4091153 & -6595.216794 & -128.869786 & 4297.509375 \\
\hline
\end{tabular}

Table 4 Energy consumption carbon emissions of various factors cumulative effect in 2012 (Unit: 10,000 tons)

\begin{tabular}{cccccc}
\hline Time & $\begin{array}{c}\text { Economic } \\
\text { Growth }\end{array}$ & $\begin{array}{c}\text { Industrial } \\
\text { Structure }\end{array}$ & $\begin{array}{c}\text { Energy } \\
\text { Intensity }\end{array}$ & $\begin{array}{c}\text { Energy } \\
\text { Consumption } \\
\text { Structure }\end{array}$ & Complex \\
\hline 2004 & 2249.510267 & 201.7277551 & -1121.748243 & -6.168702358 & 1323.321077 \\
2005 & 3425.197751 & 539.7878005 & -3004.108608 & 49.61988473 & 1010.496828 \\
2006 & 7111.298709 & 948.8460665 & -5274.425428 & 138.0939942 & 2923.813342 \\
2007 & 12249.76227 & 1432.622227 & -8441.059533 & -66.28286427 & 5175.042096 \\
2008 & 18804.39443 & 1943.451245 & -12824.51823 & -16.11261772 & 7907.214827 \\
2009 & 25256.49913 & 2176.711992 & -16833.74507 & 161.4496962 & 10760.91574 \\
2010 & 33576.51176 & 2609.304697 & -22174.67182 & 203.8989999 & 14215.04363 \\
2011 & 43715.3513 & 3220.342078 & -28707.13827 & 99.58104043 & 18328.13614 \\
2012 & 54383.53814 & 3573.751194 & -35302.35507 & -29.28874557 & 22625.64552 \\
\hline Actund
\end{tabular}

According to table 3 and table 4 can get cumulative effect contribution of each factor in 2012 and the year by year effect contribution of each factor in 2004-2012. The results are shown in Fig. 1, Fig. 2. 


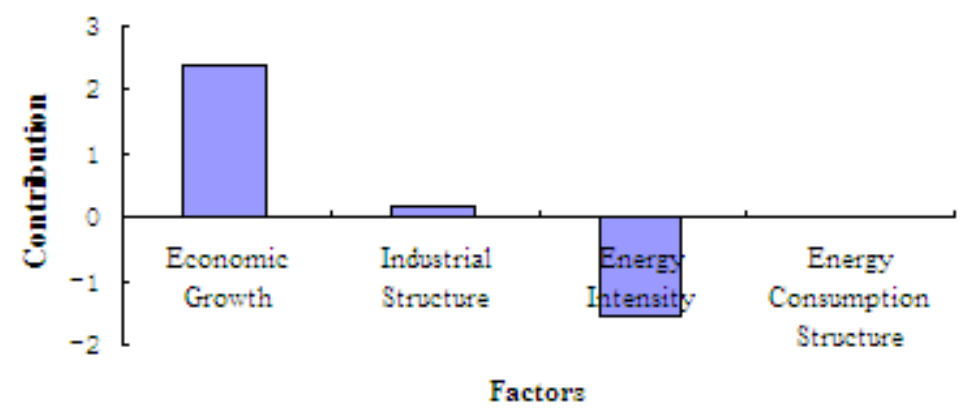

Fig. 1 Cumulative effect contribution in 2012

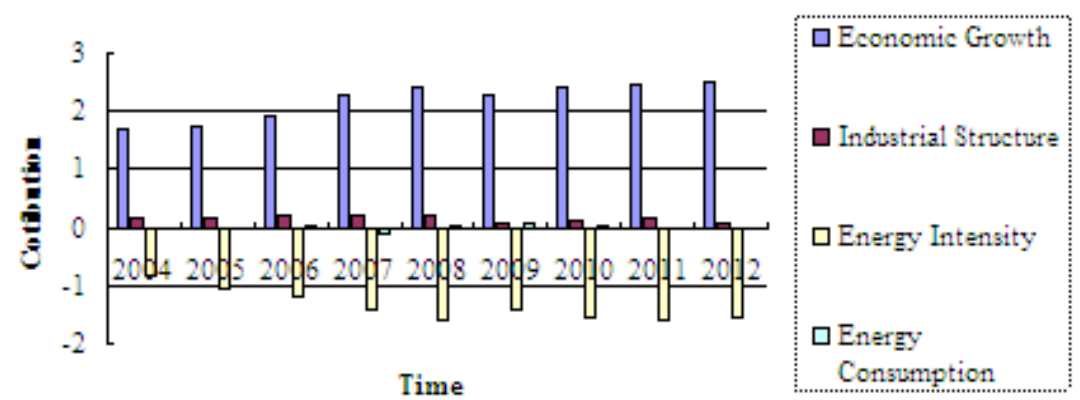

Fig. 2 Year by year effect contribution in 2004-2012

As can be seen from Fig.1 and 2, economic growth is the largest contribution source; energy intensity is greatest negative contribution source; relatively speaking, industrial structure and energy consumption structure are smaller contribution.

\section{Conclusion}

From the above calculation and analysis can find that:

(1) Economic growth is the main factor in the growth of energy consumption carbon emission in Shanxi Province. So it requires the government to formulate scientific and rational development policies to ensure the coordinated development and green development of the economy.

(2) Energy intensity is the main negative factor in the growth of energy consumption carbon emission in Shanxi Province which has a good inhibitory effect to reduce carbon emissions. So it requires the government to encourage scientific research and improve energy efficiency and output level.

(3) The industrial structure of Shanxi province is not reasonable which must increase carbon emissions. It needs to adjust the industrial structure, carry out the integration of resources and accelerate the pace of upgrading the product.

\section{References}

[1]. Song Jiekun."Factor Decomposition of Carbon Emissions from Energy Consumption of Shandong Province Based on LMDI,” Resources Science, pp.35-41,Vol.34 No.1 Jan.2012.(in Chinese)

[2]. Zhang Wei, Zhang Jinsuo, Zou Shaohui and Xu Jian.” Factor decomposition of carbon emissions from energy consumption of Shaanxi province based on LMDI,” Journal of Arid Land Resources and Environment, pp.26-31, Vol.27 No.9 Sep.2013.(in Chinese)

[3]. Wang C, Chen J and Zhou J." Decomposition of energy-related $\mathrm{CO}_{2}$ emission in China: 1957-2000,” Energy, 2005. Pp.73-83.

[4]. Liu L and I'an Y.”Using LMDI method to analyze the change of China'.s industrial $\mathrm{CO}_{2}$ emissions from final fuel use: An empirical analysis”, Energy Policy, 2007. Pp.5892-5900. 
[5]. C. Ma, D. I.Stem.” Biomass and China's carbon emissions: A missing piece of carbon decomposition,” Energy Policy, 2008, pp.2517-2526.

[6]. IPCC. National greenhouse gas inventory Guide, Japan Institute for global environmental strategy.2006.

[7]. Shanxi Statistical Yearbook, www. stats-sx. Gov. Cn. 2015. 